\title{
Tantalum oxide thin films as protective coatings for sensors
}

\author{
Christensen, Carsten; Reus, Roger De; Bouwstra, Siebe
}

Published in:

Twelfth IEEE International Conference on Micro Electro Mechanical Systems, 1999. MEMS '99.

Link to article, DOI:

10.1109/MEMSYS.1999.746832

Publication date:

1999

Document Version

Publisher's PDF, also known as Version of record

Link back to DTU Orbit

Citation (APA):

Christensen, C., Reus, R. D., \& Bouwstra, S. (1999). Tantalum oxide thin films as protective coatings for sensors. In Twelfth IEEE International Conference on Micro Electro Mechanical Systems, 1999. MEMS '99. (pp. 267-272). IEEE. International Conference on Micro Electro Mechanical Systems https://doi.org/10.1109/MEMSYS.1999.746832

\section{General rights}

Copyright and moral rights for the publications made accessible in the public portal are retained by the authors and/or other copyright owners and it is a condition of accessing publications that users recognise and abide by the legal requirements associated with these rights.

- Users may download and print one copy of any publication from the public portal for the purpose of private study or research.

- You may not further distribute the material or use it for any profit-making activity or commercial gain

- You may freely distribute the URL identifying the publication in the public portal 


\title{
Tantalum oxide thin films as protective coatings for sensors
}

\author{
Carsten Christensen, Roger de Reus, and Siebe Bouwstra \\ Mikroelektronik Centret \\ Technical University of Denmark, Building 345 East, DK-2800 Lyngby, Denmark \\ e-mail: cc@mic.dtu.dk,reus@mic.dtu.dk, sb@mic.dtu.dk
}

\begin{abstract}
Reactively sputtered tantalum oxide thin-films have been investigated as protective coating for aggressive media exposed sensors.

Tantalum oxide is shown to be chemically very robust. The etch rate in aqueous potassium hydroxide with $\mathrm{pH} 11$ at $140{ }^{\circ} \mathrm{C}$ is lower than $0.008 \AA / \mathrm{h}$. Etching in liquids with $\mathrm{pH}$ values in the range from $\mathrm{pH} 2-11$ have generally given etch rates below 0.04 $\AA / h$. On the other hand patterning is possible in hydrofluoric acid. Further, the passivation behaviour of amorphous tantalum oxide and polycrystalline $\mathrm{Ta}_{2} \mathrm{O}_{5}$ is different in buffered hydrofluoric acid.

By ex-situ annealing in $\mathrm{O}_{2}$ the residual thin-film stress can be altered from compressive to tensile and annealing at $450{ }^{\circ} \mathrm{C}$ for 30 minutes gives a stress-free film.

The step coverage of the sputter deposited amorphous tantalum oxide is reasonable, but metallisation lines are hard to cover. Sputtered tantalum oxide exhibits high dielectric strength and the pinhole density for $0.5 \mu \mathrm{m}$ thick films is below $3 \mathrm{~cm}^{-2}$.
\end{abstract}

\section{Introduction}

Packaging of a sensor is very different from conventional IC packaging, where the issue can be addressed as "post processing". The main reason for this is, that several signals are handled in sensor applications, e.g. mechanical, thermal, chemical signals, to which the sensor requires a transparent window for the measurands of interest, while microelectronics involves only electrical signals. Therefore, packaging of a sensor is more demanding and should be addressed right from the design stage [1].

For applications operating in aggressive liquid media, e.g. pressure sensors, the demands are very severe $[2,3,4]$. Here the outer layer packaging material should be extremely stable. In addition, it is an advantage that the packaging material can serve multiple purposes in the sensor system. Protective coatings applied at wafer-level (zero order packaging) reduce requirements on packaging on chip level (first order packaging).

Figure 1 shows a straightforward concept for a differential pressure sensor for aggressive media application, based on the conventional piezoresistive pressure sensor. Applying protective coatings as a solution to this sensor concept requires a number of properties for the coating to fulfil, a short list includes:

1. Corrosion resistance: the maximum allowable thickness of the coating and minimum required lifetime sets the upper limit of the etch rate in the media of interest.

2. Low residual stress and small thickness: to limit the reduction of sensitivity due to stiffness changes in the membrane.
3. Step coverage: poor coverage over interconnects and contact windows are sites where degradation of the sensor will initiate.

4. Pinhole density: usually no pinholes are allowed in the exposed area of the sensor. Etchants will penetrate the coating and degrade electrically active components or underetch, eventually resulting in an undesired lift-off of the coating. In case the pinholes are due to particulate contamination, the pinholes may be eliminated by growing thicker films.

5. Electrical properties: a dielectric film is required to insulate electrical components on the sensor from electrically conducting media.

6. Patternable: in many cases it is desired to pattern the protective coating for access to bond pads. Patterning in a batch process, such as wet etching, is preferred.

7. Double sided deposition for protection of both sides of the differential pressure sensor.

8. Coverage of sharp corners: a conformal coating is required.

9. Coverage of deep cavities: a conformal coating is required down to the bottom of the cavity.

Furthermore, good adhesion and good diffusion barrier properties are desired. Although the above requirements all are essential, corrosion resistance (1) and low pinhole density (4) may be most important, since these properties cannot be circumvented by alternate sensor designs or materials combinations.

Protection against acidic environments usually is not a problem and conventional materials from semiconductor industry can be used to encapsulate, a.o., metal lines on silicon substrates, which do not etch in, e.g. hydrofluoric acid [3]. Alkaline environments form a greater challenge. The specifications for our sensor applications are a minimum lifetime of ten years for maximum film thickness of one micron in alkaline solutions with $\mathrm{pH} 11$ and temperatures up to $120^{\circ} \mathrm{C}$. Other media of interest include refrigerants, lubricants, and hydraulic oils containing additives. Grain boundaries are expected to be weak points for corrosion resistance, very similar to diffusion barrier performance [10].

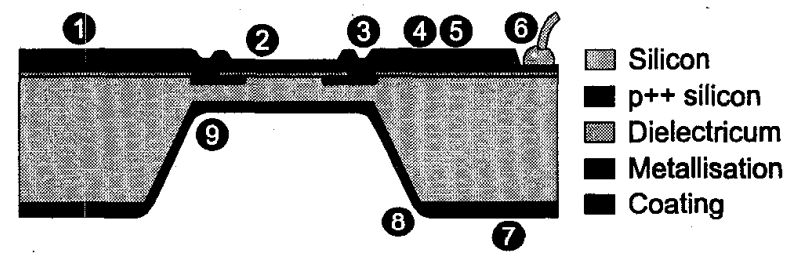

Figure 1: Requirements for protective coatings. A cross section of a typical piezoresistive pressure sensor is shown. Several critical properties for the coating are identified. Refer to the text for an explanation of the running numbers. 
Supported by recent investigations [5] we believe that amorphous materials, although metastable, are excellent candidates for corrosion resistant coatings.

The use of tantalum, tantalum alloys, and tantalum oxide has already been suggested for sensor purposes [6,7]. Besides, tantalum is used in chemical processing equipment because it is extremely stable. The reason for this is the formation of a thin amorphous tantalum oxide layer at the surface, which is chemically very inert [8]. Deposition of tantalum and its oxides and nitrides can be done by physical vapour deposition, by chemical vapour deposition, or by thermal oxidation. This makes the use of these materials very flexible.

In this paper, we report the characteristics of tantalum oxide as a coating material.

\section{Experimental}

Reactively sputtered tantalum oxide films with varying thicknesses from $200 \mathrm{~nm}$ up to $1 \mu \mathrm{m}$ were deposited on $4 " \mathrm{Si}$ $<100>$ substrates from a tantalum target in a DC sputter system with a base pressure better than $2 \times 10^{-6} \mathrm{~Pa}$. The $2^{\prime \prime} \mathrm{Ta}$ sputter target is normally positioned at a distance $213 \mathrm{~mm}$ from the substrate and tilted by $33^{\circ}$ with respect to the sample surface normal. The substrate was rotated during deposition yielding a thickness variation from centre to edge of $2.5 \%$. The substrate holder has a built-in heater enabling temperatures up to $700{ }^{\circ} \mathrm{C}$. The sputter gas was a mixture of $5 \mathrm{sccm} \mathrm{O}_{2}$ and $20 \mathrm{sccm}$ Ar at a pressure of $3.7 \times 10^{-1} \mathrm{~Pa}$. The deposition rate was approx. 1 $\AA / \mathrm{min} / \mathrm{W}$.

Isochronal annealing of the tantalum oxide films was done ex-situ in an open furnace with a flow of $3 \mathrm{slm} \mathrm{O}_{2}$ for 30 minutes at temperatures ranging from $100^{\circ} \mathrm{C}$ to $700^{\circ} \mathrm{C}$.

Thicknesses of the tantalum oxide films were determined by variable angle scanning ellipsometry.

Wafer curvature and roughness of the films were measured using a stylus-type profilometer. Stress was derived from wafer

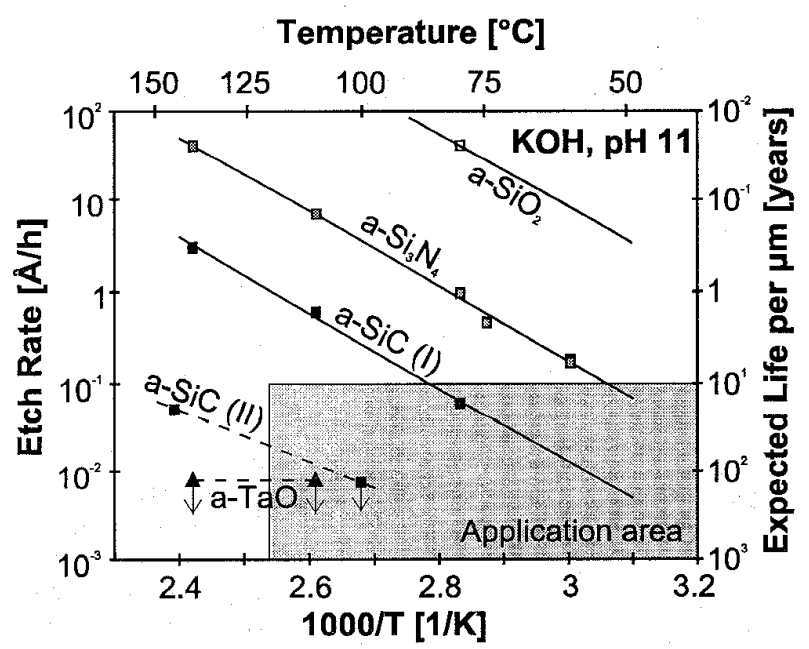

Figure 2: Etch rates of several thin film systems in aqueous $K O H \mathrm{pH}$ ll. The application area is marked. For a-TaO an upper limit is given (indicated by arrows) since no detectable loss occurred after 9 months of exposure, The etch rates for the other systems are obtained from Refs. [3,4]. curvature difference measurements.

Simulations of the step coverage behaviour as a function of the tilt angle were performed using the SUPREME Athena Elite computer code [9].

\section{Results}

\section{Morphology}

The structures for the as-deposited tantalum oxide films were amorphous. However, by ex-situ annealing in $\mathrm{O}_{2}$ for $30 \mathrm{~min}$. at temperatures of $600^{\circ}$ or above the amorphous tantalum oxide (a-TaO) transformed into polycrystalline $\mathrm{Ta}_{2} \mathrm{O}_{5}$, as shown by $\mathrm{X}$-ray diffraction measurements. The change in morphology was also observed optically, and by measuring the roughness $R_{a}$ of the film. $R_{a}$ increased from $3 \AA$ as-deposited to $110 \AA$ after annealing at $700^{\circ} \mathrm{C}$.

These observations agree well with those reported in Refs. $[10,11]$. There, tantalum thin films were completely oxidised at $500{ }^{\circ} \mathrm{C}$ within $1 \mathrm{~h}$ with a composition close to that of the stoichiometric $\mathrm{Ta}_{2} \mathrm{O}_{5}$. The crystallisation temperature was $650^{\circ} \mathrm{C}$.

\section{Etching Characteristics}

The a-TaO films were exposed to various media.

In aqueous potassium hydroxide solutions of $\mathrm{pH} \mathrm{11}$, after exposure for 9 months at temperatures of $110^{\circ} \mathrm{C}$ or $140^{\circ} \mathrm{C}$, no thickness change could be observed by ellipsometry. A conservative estimate of the resolution of the ellipsometry method is $50 \AA$, probably in practice more like $10 \AA$. This corresponds to an upper limit of the etch rate of $0.008 \AA \mathrm{h}$, thus extremely stable in comparison to other materials, see Figure 2. Further in DI-water of $\mathrm{pH} 7$ and in aqueous hydrochloric acid solutions of $\mathrm{pH} 2$ no thickness changes could be observed after 50 days of exposure. This corresponds to an upper limit of the etch rate of $0.04 \AA / h$.

In aqueous hydrofluoric acid (HF) solutions, the etch rate of $\mathrm{a}-\mathrm{TaO}$ is concentration dependent. In Figure 3 the etch rates of $\mathrm{a}-\mathrm{TaO}$ at $\mathrm{RT}$ as a function of HF concentration are given. It can be observed that the etch rate increases exponentially with $\mathrm{HF}$ concentration. At a HF concentration of $5 \%$ the etch rate is $320 \pm 6 \AA / \mathrm{h}$, increasing to $(1.4 \pm 0.1) \times 10^{5} \AA / \mathrm{h}$ at $50 \%$.

In concentrated buffered hydrofluoric acid (BHF) at RT, the etch rate has been determined to $10 \pm 1 \AA / \mathrm{h}$.

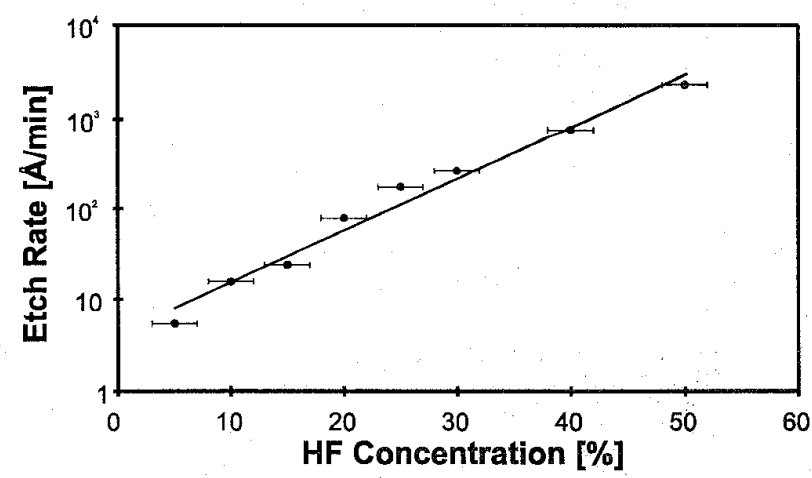

Figure 3: Etch rate of amorphous tantalum oxide at $R T$ as a function of the hydrofluoric acid concentration. 
The difference in passivation behaviour of polycrystalline $\mathrm{Ta}_{2} \mathrm{O}_{5}$ and $\mathrm{a}-\mathrm{TaO}$ was observed after exposing a film to $\mathrm{BHF}$ after exsitu annealing at $600{ }^{\circ} \mathrm{C}$. The formed polycrystalline $\mathrm{Ta}_{2} \mathrm{O}_{5}$ film was "lifted" away from the silicon surface within a few hours. This is probably the result of diffusion of the reagents along grain boundaries $[10,11]$, and subsequent etching of the underlying material.

\section{Step Coverage}

An important property for a thin film protective coating is the step coverage of the film on microstructured surfaces. A $1 \mu \mathrm{m}$ thick a-TaO film was deposited at $200{ }^{\circ} \mathrm{C}$ onto a $<100>\mathrm{Si}$ substrate containing anisotropically etched cavities with depths of $350 \mu \mathrm{m}$. Cross section SEM pictures of the structures from the bottom and top of the cavity are shown in Figure $4 \mathrm{c}$ and Figure 4 d, respectively.

From these pictures, a thickness ratio of approx. $70 \%$ was determined between the sidewall of the hole and the flat surface. The sidewall makes an angle of $54.7^{\circ}$ with respect to the top surface yielding an opening angle of $125.3^{\circ}$ and $234.7^{\circ}$ for the bottom and top part of the cavity, respectively.
Figure $4 \mathrm{~b}$ shows a SEM picture cross section of a $1 \mu \mathrm{m}$ tantalum oxide film deposited onto a $5000 \AA$ thick aluminium wire formed by a lift off process. The edge of the aluminium wire makes an angle of approx. $70-80^{\circ}$ with respect to the surface yielding an opening angle of approx. $100-110^{\circ}$. Voids are observed starting at the bottom corner of the interface between the aluminium wire and the substrate underneath. The voids extend all the way to the top surface. This was confirmed by exposure of aluminium pads of size $1 \times 1 \mathrm{~mm}^{2}$ to $\mathrm{KOH} \mathrm{pH} 14$ for $30 \mathrm{~min}$. Figure 5 shows photographs of the aluminium pads before and after the exposure. The pads are heavily attacked, whereas the anisotropically etched line into the silicon substrate shown to the right in the photos is not attacked by the exposure. The poor step coverage of the aluminium wire with a small opening angle is a consequence of the sputtering process, where the deposition at each point is merely determined by the opening angle. The opening angle gets very narrow in the corner as the thickness increases resulting in closing of the gap, and the voids are formed.
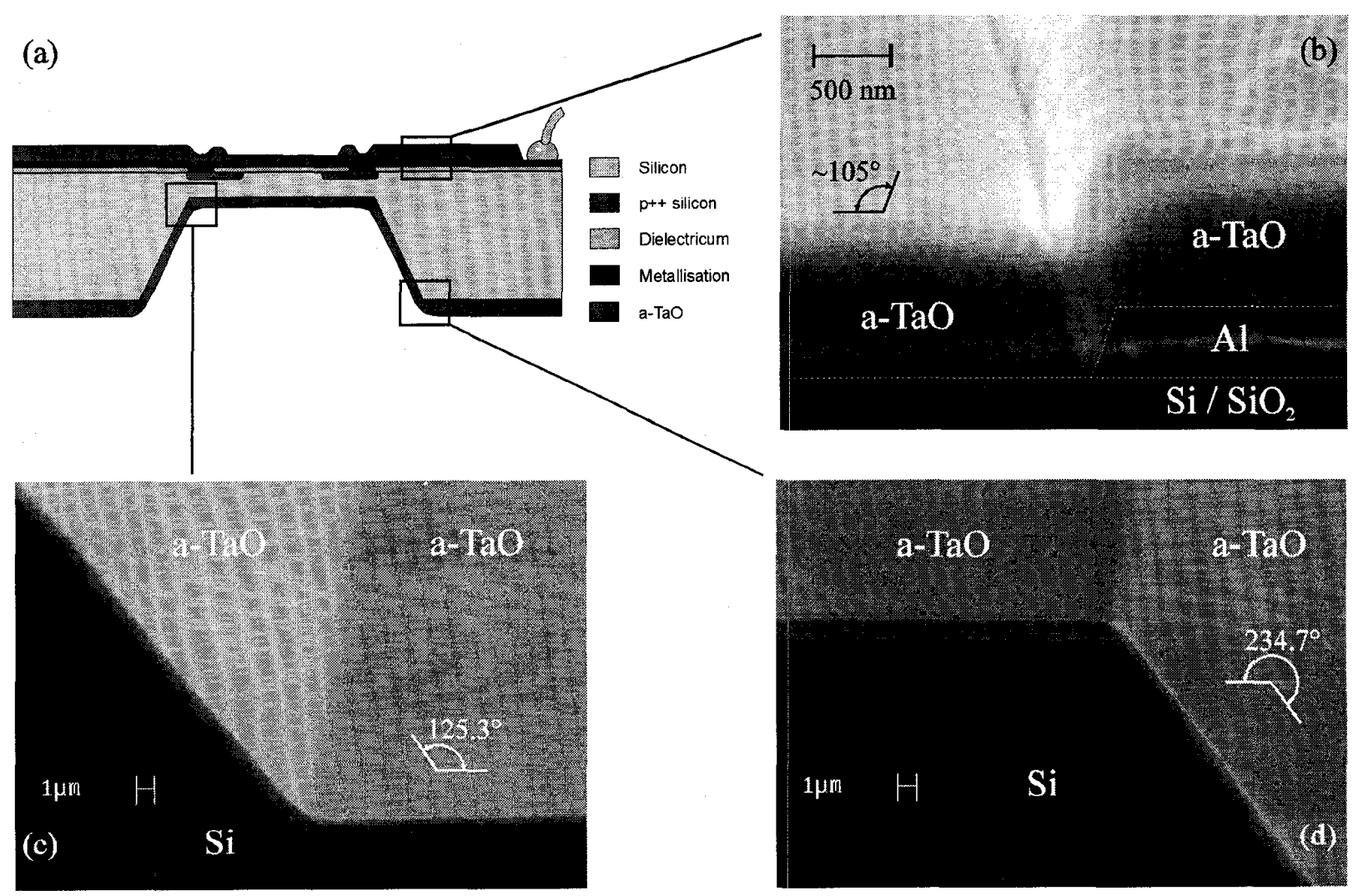

Figure 4: Cross sections of 1 m tantalum oxide film deposited at $200^{\circ} \mathrm{C}$ on a sensor chip. A) Schematic drawing of the sensor chip. B) $5000 \AA$ aluminium interconnection wire on an oxidised silicon substrate. The white lines are added to emphasise the sample structure. C) Bottom of an anisotropically etched $<100>$ silicon cavity. D) Top of cavity. 

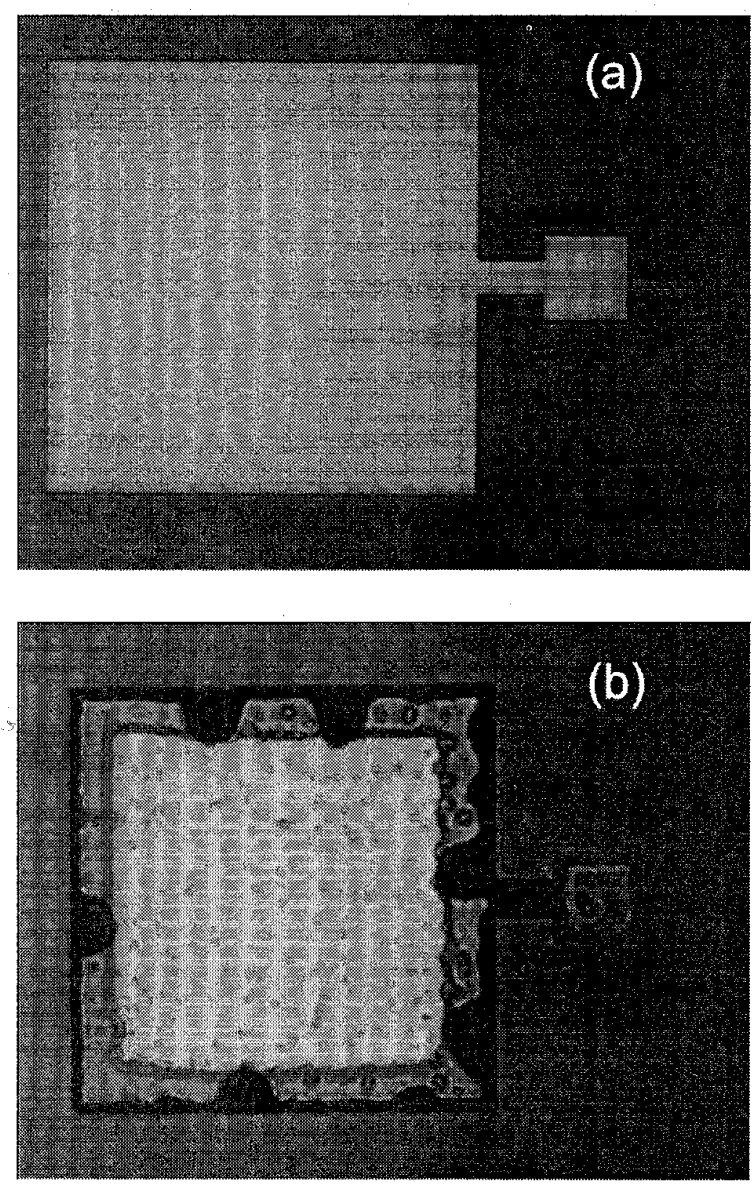

Figure 5: Photographs of the results of exposure to $\mathrm{KOH} \mathrm{pH} 14$ for $30 \mathrm{~min}$ at $80^{\circ} \mathrm{C}$ of aluminium pads of size $I \times I \mathrm{~mm}^{2}$ and of thickness $0.5 \mu \mathrm{m}$ covered with $I \mu \mathrm{m}$ amorphous tantalum oxide film deposited at $200^{\circ} \mathrm{C}$. A) Before exposure. B) After exposure.
To optimise the coverage on steps, simulations were made to find the optimum deposition parameters with regard to the tilt angle between the source and the substrate. The simulated profiles agreed very well with the experiments.

Figure 6 shows the minimum thicknesses as result of the simulations for different opening angles $\varphi$ and tilt angles $\psi$. The minimum thicknesses in the vertical direction $h_{\min }$ and at the sidewall $h_{w}$ are defined in the right part of the figure. The optimum coverage is obtained where $h_{\min }$ equals $h_{w}$ and for $\varphi=$ 111.8 and $\varphi=125^{\circ}$ this is achieved for $\psi$ slightly above $40^{\circ}$.

\section{Stress}

The residual stress of the tantalum oxide thin films was measured after ex-situ annealing for 30 minutes in $\mathrm{O}_{2}$ at temperatures ranging from $100{ }^{\circ} \mathrm{C}$ to $700{ }^{\circ} \mathrm{C}$. Figure 7 shows residual stress for a-TaO deposited at $\mathrm{RT}$ as a function of annealing temperature. The stress was transformed from initial $200 \mathrm{MPa}$ compressive at RT to $250 \mathrm{MPa}$ tensile stress after annealing at $700{ }^{\circ} \mathrm{C}$. Stress-free films can be obtained by annealing at $425^{\circ} \mathrm{C}$. Although, the material starts to crystallise above $\sim 550^{\circ} \mathrm{C}$ no sudden change in the stress was observed.

\section{Dielectric Strength}

The dielectric strengths of $3000 \AA$ thick a-TaO films were determined by forming capacitors. Aluminium layers with a thickness of $0.5 \mu \mathrm{m}$ were deposited by e-gun deposition through a shadow mask to form the top electrode. The silicon substrate wafer itself is the bottom electrode. The capacitors were tested with a DC voltage increase of $1 \mathrm{~V} / \mathrm{s}$ under accumulation conditions. The maximum voltage was $40 \mathrm{~V}$ and electric breakdown was not observed, yielding a dielectric strength higher than $1 \times 10^{6} \mathrm{~V} / \mathrm{cm}$.

\section{Pinhole density}

The pinhole density of $0.5 \mu \mathrm{m}$ thick a-TaO films deposited at $200^{\circ} \mathrm{C}$ has been measured to be below $3 \mathrm{~cm}^{-2}$. The pinhole density may be decreased by growing larger thicknesses at higher temperatures.
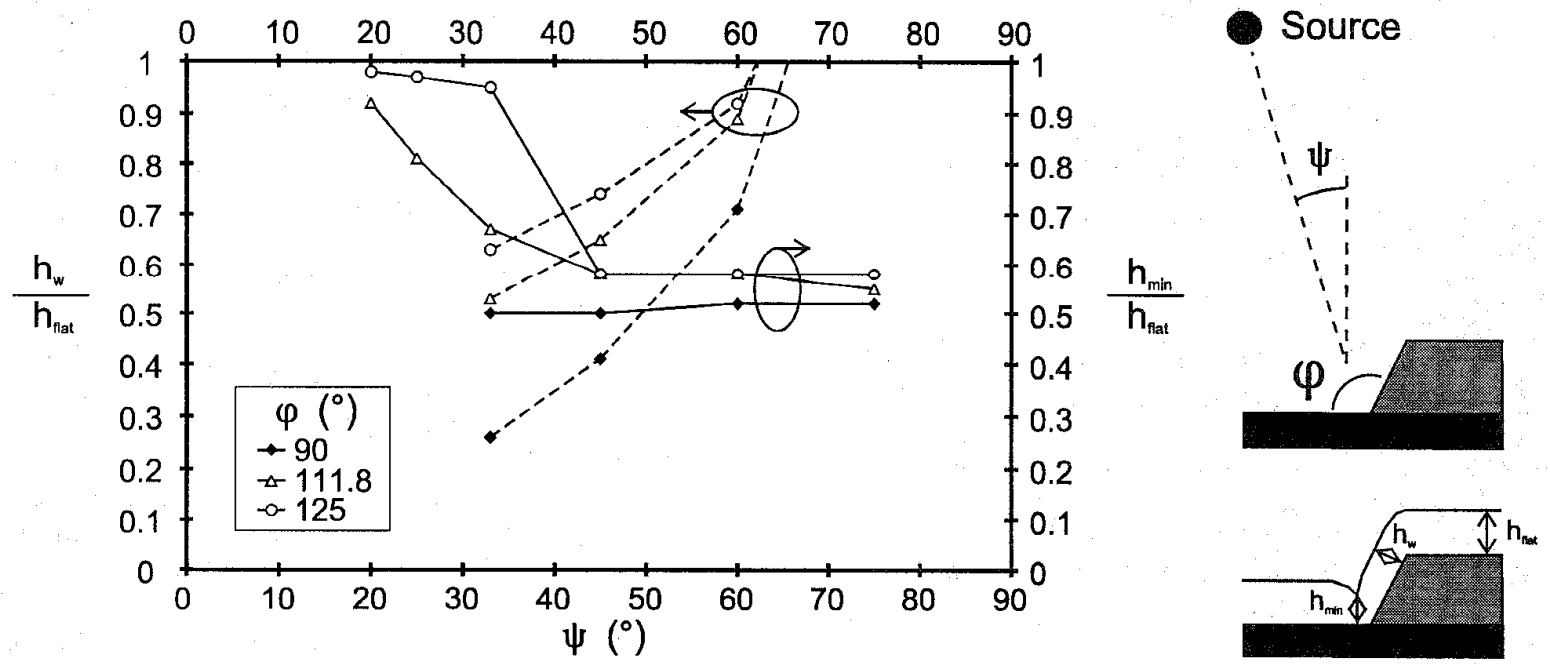

Figure 6: Simulation results for the minimum thicknesses obtained for different tilt angles and opening angles. 


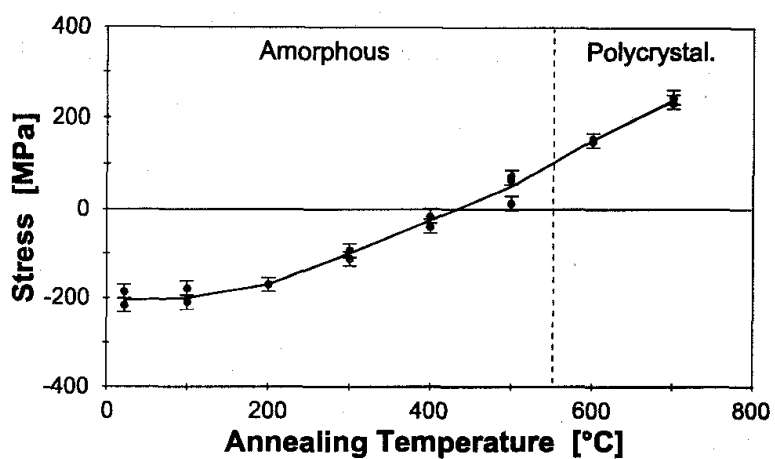

Figure 7: The measured stress of $3000 \AA$ tantalum oxide film deposited at RT as a function of ex-situ annealing temperature in $\mathrm{O}_{2}$. Annealing times was $30 \mathrm{~min}$.

\section{Discussion}

A very important result from the above experiments is the extremely high resistance of a- $\mathrm{TaO}$ to alkaline solutions. In comparison with many other materials $[3,4]$ a- $\mathrm{TaO}$ is a superior coating material. This makes the material very useful for most refrigerants, central heating systems, white goods applications, and other industrial products of the same kind, where the medium used is water with a $\mathrm{pH}$ in the range of 2-11.

The observation that the material can be etched in HF offers the possibility for patterning in batch processes using resist as a mask.

Thin-film stress may be a drawback for various applications. The residual stress in the as-deposited a-TaO films is compressive which helps avoiding crack growth in the film. Moreover, by ex-situ annealing in $\mathrm{O}_{2}$ at a moderate temperature of $425{ }^{\circ} \mathrm{C}$ for 30 minutes, the stress can be eliminated and the material is still amorphous. However, annealing at temperatures in excess of $\sim 550{ }^{\circ} \mathrm{C}$ yields polycrystalline $\mathrm{Ta}_{2} \mathrm{O}_{5}$. The polycrystalline structure is undesired because reactants may diffuse through the film along the grain boundaries $[10,11]$ and subsequently etch the silicon surface. This behaviour was emulated by etching polycrystalline $\mathrm{Ta}_{2} \mathrm{O}_{5}$ films in BHF, and the films were "lifted" from the silicon substrate within a few hours. This has to be compared with the a-TaO films able to withstand BHF for at least 100 hours.

The dielectric strength of the a-TaO higher than $1 \times 10^{6} \mathrm{~V} / \mathrm{cm}$ is similar to the dielectric strength of other insulators used in micromechanics and electronics: silicon dioxide and lowpressure chemical vapour deposition (LPCVD) silicon nitride. Thus, $\mathrm{a}-\mathrm{TaO}$ can be very well applied as insulator material (see also Ref. [7]).

The reactive sputter process for depositing tantalum oxide limits the topology of the surface to be covered. As seen from Figure $4 \mathrm{~b}$ voids are probably formed because of the steep slope between the sidewall of the aluminium wire and the substrate surface. On the other hand, anisotropically etched structures with an angle of $54.7^{\circ}$ show very good step coverage. This implies a critical angle for the used experimental conditions. Simulations show that by changing the deposition angles an improved step coverage can be achieved. Research is ongoing to determine this angle and characterise the influence of the deposition parameters (in particular substrate heating, pressure and deposition rate). Deposition of tantalum oxide by an LPCVD process can improve the step coverage a lot. This process is used for storage capacitors in dynamic random access memory (DRAM) applications at a moderate process temperature of $450^{\circ} \mathrm{C}$ [12]. There, the thickness ratio was better than $90 \%$ between the top and the side of a $0.35 \mu \mathrm{m}$ wide and $0.70 \mu \mathrm{m}$ deep trench.

\section{Conclusions}

High quality reactively sputtered a-TaO thin-films were deposited on silicon $\langle 100\rangle$ substrates. The material is demonstrated to exhibit very good qualities as a coating material. Especially the corrosion resistance towards aqueous media with $\mathrm{pH}$ in the range of 2-11 makes the material very useful as protective coating for sensor applications. Further, the material can be patterned by etching in $\mathrm{HF}$.

The etch resistance of a- $\mathrm{TaO}$ has been shown superior in comparison to polycrystalline $\mathrm{Ta}_{2} \mathrm{O}_{5}$.

The stress of tantalum oxide can be controlled from $200 \mathrm{MPa}$ compressive to tensile by annealing in $\mathrm{O}_{2}$ and a stress-free film can be obtained by annealing at temperatures slightly above $400{ }^{\circ} \mathrm{C}$. In addition, a- $\mathrm{TaO}$ has as high a dielectric strength as insulator materials used in microelectronics.

The sputter process of a-TaO exhibits good step coverage although some constraints of the surface topology to be covered have to be addressed.

In conclusion, reactively sputtered tantalum oxide is a very useful coating material.

\section{Acknowledgements}

This work has been supported by the 'Materials for Advanced Packaging' program under the Materials Development Program supported by the Danish Agency for Trade and Industry, the Danish Natural Science Research Foundation, and the Danish Technical Science Research Foundation. In addition, the authors would like to thank their colleagues at Mikroelektronik Centret, Grundfos A/S, and Danfoss A/S for their collaboration in this research. Undergraduate students Frank Engel Rasmussen and Rasmus Glarborg Jensen are acknowledged for their valuable stress measurements. Wouter Olthuis (MESA Institute, Technical University of Twente, The Netherlands) is acknowledged for supplying us with the first tantalum oxide samples.

\section{References}

1 K. Najafi: "Silicon micromachining technologies: future needs and challenges", Micromachining and Microfabrication Process Technology II, Proc. SPIE 2879, 1996, pp. 206-215.

2 K. Dyrbye, T.R. Brown, and G.F. Eriksen: "Packaging of physical sensors for aggressive media applications", J. Micromech. Microeng. 6, 1996, pp. 187-192.

3 G.F. Eriksen and K. Dyrbye: "Protective coatings in harsh environments", J. Micromech. Microeng. 6, 1996, pp. 55-57. 
4 R. de Reus, C. Christensen, S. Weichel, S. Bouwstra, J. Janting, G. Friis Eriksen, K. Dyrbye, T. Romedahl Brown, J.P. Krog, O. Søndergaard Jensen, and P. Gravesen: "Reliability of industrial packaging for microsystems", Microelectronics Reliability 38, 1998, pp. 1251-1260.

5 P. Andersen: "Protection of micromechanical pressure sensors with metallic glasses", Ph.D. thesis, University of Aarhus, Århus, Denmark, 1998.

6 M.A. Gretillat, C. Lindner, A. Dommann, G. Staufert, N.F. de Rooij, and M.A. Nicolet: "Surface-micromachined Ta-Si$\mathrm{N}$ beams for use in micromechanics", J. Micromech. Microeng. 8, 1998, pp. 88-90.

7 W. Olthuis, A.J. Sprenkels, J.G. Bomer, and P. Bergveld: "Planar $\mathrm{Ta}_{2} \mathrm{O}_{5}$-covered interdigitated electrolyteconductivity sensors on an insulating substrate", Proc. Eurosensors X, Leuven, Belgium, 1996, pp. 745-748.

8 U. Gramberg, M. Renner, and H. Diekmann: "Tantalum as a material of construction for the chemical processing industry - A critical survey", Materials and Corrosion 46, 1995, pp. 689-700.

9 SUPREME simulation tool, Silvaco International, 1996.

10 R. de Reus, F.W. Saris, G.J. Van der Kolk, C. Witmer, B. Dam, D.H.A. Blank, D.J. Adelerhof, and J. Flokstra: "Buffer layers for superconducting $\mathrm{Y}-\mathrm{Ba}-\mathrm{Cu}-\mathrm{O}$ thin films on silicon and $\mathrm{SiO}_{2} "$, Mat. Sci. Eng. B7, 1990, pp. 135-147.

11 O. Thomas, F.M. d'Heurle, and A. Charai: "Reacted amorphous layers: tantalum and niobium oxides", Phil. Mag. B 58, 1988, pp. 529-538.

12 W.R. Hitchens, W.C. Krusell, and D.M. Dobkin: "Tantalum oxide thin films for direct applications by low pressure chemical vapour deposition", J. Electrochem. Soc. 140, 1993, pp. 2615-2621. 